\title{
ECZEMA; FREQUENCY OF DIFFERENT TYPES IN A TERTIARY CARE HOSPITAL
}

1. FCPS (Derma), Assistant Professor, Dept of Dermatology,

Hamdard college of Medicine and Dentistry.

2. FCPS (Derma), Diplomate (RCPSG).

Assistant Professor

Dept of Dermatology DIMC, DUHS

3. Assistant Professor,

Hamdard College of Medicine \& Dentistry

4. Professor of Dermatology, DUHS.

Correspondence Address:

Dr. Humaira Maryum Agha.

Department of Dermatology.

Hamdard University Hospital,

Taj Medical Complex,

M.A. Jinnah Road, Karachi.

humairamaryum@yahoo.com

Article received on:

26/10/2015

Accepted for publication:

10/12/2015

Received after proof reading:

$13 / 01 / 2016$

\section{Dr. Humaira Maryum Agha', Dr. Sadaf Ahmed Asim², Dr. M. Zafar Alam ${ }^{3}$, Prof. Zarnaz Wahid ${ }^{4}$}

ABSTRACT... Objectives: To determine the frequency of different types of eczema in patients presenting in a tertiary care hospital. Study Design: Cross sectional descriptive type of study. Setting: Hamdard University Hospital Karachi. Period: January 2013 till December 2013. Patients and Methods: All new cases of any type of eczema were registered by nonprobability convenient sampling. Total 192 patients of both genders and all ages were enrolled after taking informed consent. Diagnosis was made on detailed history and clinical examination by consultant dermatologist. All specific and relevant investigations were done according to requirement. Patients were divided in two groups, exogenous eczema and endogenous eczema, for convenience. Data was analyzed by the latest version of SPSS. Results: There were 192 patients, out of which $52.08 \%$ were males and $47.91 \%$ females. Out of the total presented patients $50 \%$ had endogenous eczema, $43.37 \%$ had exogenous eczema and $25.62 \%$ had unspecified eczema. In endogenous group $11.45 \%$ had hand dermatitis followed by seborrhoeic dermatitis, atopic dermatitis and asteatotic eczema in descending frequency of presentation. Pityriasis alba, discoid eczema and pompholyx were seen less frequent. In exogenous eczema allergic contact dermatitis was seen in $14.06 \%$ patients, while irritant contact dermatitis in $11.45 \%$ patients. Infective eczema and photo-allergic eczema were seen in small number of patients. Conclusion: It was found in this study that allergic contact dermatitis was most common type of eczema followed by other types. Whatever the type is, eczema can be treated, symptoms can be relieved and recurrences can be prevented by appropriate therapy. All types of eczema affect patient's quality of life adversely. However, they can be prevented by educating patients and their relatives to take adequate safety measures like using good quality emollients prophylactically.

Key words: Eczema, Papulo-vesiculation, Spongiosis, Acanthosis, Lympho-histiocytic infiltrate, Endogenous Eczema, Exogenous Eczema

Article Citation: Agha HM, Asim SAA, Alam MZ, Wahid Z. Frequency of different types of eczema in a tertiary care hospital. Professional Med J 2016;23(1):060-064. DOI: $10.17957 / T P M J / 16.3144$

\section{INTRODUCTION}

Eczema is an inflammatory skin reaction to various exogenous and/or endogenous stimuli. Clinical presentation includes itching, redness, scaling and papulovesiculation.

Histologically the condition is characterized by intercellular edema (spongiosis), acanthosis (of varying degree) and lympho-histiocytic infiltrate in superficial perivascular area of dermis.

There is no worldwide accepted definition of eczema. Eczema and dermatitis are most of the time interchangeable terms. All eczemas are dermatitis but every type of dermatitis cannot be labeled as eczema. ${ }^{1}$

Various factors influence eczema. On the basis of these factors eczema is classified in two major groups (Table-I). ${ }^{2}$ The first group "The exogenous eczema" is related to external triggers, although inherited tendencies also play some role. Second group "The endogenous eczema" implies the conditions mediated by the processes originated within the body.

Some of these conditions are precipitated by both external and internal factors, for example hand dermatitis is endogenous but precipitated by irritants like detergents. Another category 
"unspecified eczema" is one which does not fit in any of these classes. ${ }^{3}$

\begin{tabular}{|c|c|}
\hline Exogenous eczemas & Endogenous eczemas \\
\hline Irritant eczema & Atopic eczema \\
\hline Allergic contact eczema & Seborrhoeic eczema \\
\hline $\begin{array}{l}\text { Photoallergic contact } \\
\text { eczema }\end{array}$ & Asteatotic eczema \\
\hline $\begin{array}{l}\text { Eczematous } \\
\text { polymorphic light } \\
\text { eruption }\end{array}$ & Discoid eczema \\
\hline Infective eczema & Eyelid eczema \\
\hline Dermatophytide & $\begin{array}{l}\text { Eczematous drug } \\
\text { eruptions }\end{array}$ \\
\hline \multirow[t]{7}{*}{ Post-traumatic eczema } & $\begin{array}{l}\text { Chronic superficial } \\
\text { scaly dermatitis }\end{array}$ \\
\hline & Pityriasis alba \\
\hline & Hand eczema \\
\hline & Venous eczema \\
\hline & $\begin{array}{l}\text { Juvenile plantar } \\
\text { dermatosis }\end{array}$ \\
\hline & $\begin{array}{l}\text { Exudative discoid } \\
\text { and lichenoid chronic } \\
\text { dermatosis }\end{array}$ \\
\hline & $\begin{array}{l}\text { Metabolic eczema or } \\
\text { eczema associated } \\
\text { with systemic disease }\end{array}$ \\
\hline \multicolumn{2}{|c|}{$\begin{array}{l}\text { Table-I. Classification of the principal forms of } \\
\text { eczema }\end{array}$} \\
\hline
\end{tabular}

Eczematous dermatoses account for a large proportion of skin diseases. In developing countries it is the second major group of dermatoses after infections and infestations. ${ }^{4}$ Some types of eczema are more prevalent in particular age groups, like atopic dermatitis is common in infants and young children, similarly astaetotic eczema is common in old age. ${ }^{5}$

\section{STUDY OBJECTIVES}

\section{Aim of Study}

To determine the frequency of different types of eczema.

\section{Primary Objective}

To identify which type of eczema is more frequently seen in a tertiary care hospital.

\section{Secondary Objective}

To increase the awareness among medical professionals about this commonly occurring phenomenon.

\section{Rationale}

In Pakistan, a lot of work has been done in atopic dermatitis. As far as other forms of eczema are concerned very few studies are available. Therefore, we have undertaken a study which shows frequency of different patterns of eczema in patients presenting in a tertiary care hospital. We hope to use the findings as our baseline data to understand the pattern of skin disease and to plan dermatologic health care programs for patients in Pakistan.

\section{PATIENTS AND METHODS Study Design \\ Descriptive, Prospective, Cross-sectional.}

\section{Subject Selection and Withdrawal Inclusion Criteria}

New patients with different patterns of eczema were included.

Patients of both sexes and all age groups were included.

All indoor and outdoor patients were included in the study.

\section{Exclusion Criteria}

Follow-up cases were excluded.

Patients not willing to give consent.

\section{Study Procedures}

Study was conducted at Hamdard University Hospital Karachi, from January 2013 to December 2013. After taking informed consent patients were registered for study by convenient sampling.

\section{Selection Criteria}

Diagnosis was made by consultant dermatologist on the basis of detail history and clinical examination. Skin biopsy and patch test were performed where required. Other relevant investigations were also done according to 
need. History was taken in detail, which included occupational history, history of other allergies, socio-economic status and a family history of similar or related disease.

\section{STATISTICAL PLAN}

\section{Sample Size Determination}

A total of 192 patients with different patterns of eczema were enrolled in the study during a period of one year.

\section{Statistical Methods}

All data was entered and analyzed on latest version of SPSS. Only summary statistics will be used in analysis of the results. Percentages, mean, median, frequencies and cross-tabs were used to analyze the data.

\section{RESULT}

A total of 192 patients with different patterns of eczema were enrolled in the study during a period of one year. There were $100(52 \%)$ males and $92(47.9 \%)$ females. Out of these 192 patients, 96 (50\%) had endogenous eczema (41 females and 55 males), 66 (34.37\%) were suffering from exogenous eczema (42 females and 24 males), while $30(15.62 \%)$ patients were those who had unspecified eczema (17 females and 13 males).

Amongst these 96 patients of endogenous eczema (Table-II), hand dermatitis was most frequent presentation in $22(11.45 \%)$, followed by seborrhoaeic dermatitis in $18(9.37 \%)$ patients. Atopic dermatitis was observed in 16(8.33\%) patients and majority of them were children. Asteatotic eczema was more frequent in old age group and was seen in 13(6.77\%) patients. Ptyriasis alba, discoid eczema and pompholyx was seen in $5.72 \% 4.68 \%$ and $2.08 \%$ patients respectively. Only three $(1.56 \%)$ patients had stasis eczema.

Table-III shows patients with exogenous eczema. Out of sixty six patients 27 (14.06\%) had allergic contact dermatitis, while 22 (11.45\%) had irritant contact dermatitis. Infective eczema was seen in $5.20 \%$ and photo-allergic eczema in $3.64 \%$ patients only.

\begin{tabular}{|l|c|c|c|}
\hline Type of Eczema & Male & Female & Total \\
\hline Hand dermatitis & 12 & 10 & 22 \\
\hline Seborrhoaeic dermatitis & 11 & 7 & 18 \\
\hline Atopic dermatitis & 9 & 7 & 16 \\
\hline Asteatotic eczema & 7 & 6 & 13 \\
\hline Ptyriasis alba & 5 & 6 & 11 \\
\hline Discoid eczema & 5 & 4 & 9 \\
\hline Pompholyx & 3 & 1 & 4 \\
\hline Stasis eczema & 3 & 0 & 3 \\
\hline Total & 55 & 41 & 96 \\
\hline
\end{tabular}

Table-II. Endogenous Eczema $(n=96)$

\begin{tabular}{|l|c|c|c|}
\hline Type of Eczema & Male & Female & Total \\
\hline Allergic contact dermatitis & 10 & 17 & 27 \\
\hline Irritant contact dermatitis & 7 & 15 & 22 \\
\hline Infective eczema & 5 & 5 & 10 \\
\hline Photo-allergic dermatitis & 2 & 5 & 7 \\
\hline Total & 24 & 42 & 66 \\
\hline \multicolumn{2}{|c|}{ Table-III. Exogenous Eczema $\quad(n=66)$} \\
\hline
\end{tabular}

\section{DISCUSSION}

Internationally, literature is very scanty regarding the frequency of different types of eczema. Although a lot of work has been done in individual types of eczema like hand dermatitis, atopic dermatitis etc.

Eczema is the second major group of skin diseases after infections in many South Asian countries. . $^{4,6,7,8}$

In USA the prevalence of eczema ranges from $8.7 \%$ to $18.1 \%$ between different states in one study. ${ }^{9}$ In our country no such study of eczema prevalence is available.

We found allergic contact dermatitis in 14.06\% patients, Abhijit and thappa ${ }^{10}$ studied patients with lower leg eczema of different age groups and found allergic contact dermatitis to be most common type of eczema in $14.5 \%$ subjects, and results are comparable to our study.

Another study ${ }^{11}$ conducted at Baqai Institute of Skin Diseases shows $7.5 \%$ had patients hand dermatitis, in our study this type of eczema was found in $11.45 \%$, the difference is because of 
large sample size in the former. Males were found to be affected more than females in our study, Uzma et $\mathrm{al}^{12}$ found a male preponderance of hand dermatitis in a similar study.

Comparable results were found in a study conducted in $\mathrm{UK}^{13}$, which shows hand dermatitis in $15 \%$, seborrhoeic dermatitis in $11 \%$ and atopic dermatitis in $5 \%$ patients, in our study these eczemas were found in $11.45 \%, 9.37 \%$ and $8.33 \%$ respectively.

Muzaffar et $\mathrm{al}^{14}$, reported frequency of atopic dermatitis in $13.3 \%$ children from children's hospital Lahore. Hanifin and Reed ${ }^{15}$, reported this prevalence in $6 \%$. Our results $(8.33 \%)$ are within the range of these two figures, being close to later.

Stasis eczema was observed in $1.56 \%$ cases in our study, in another study ${ }^{13}$ it was higher (4\%), however, only localized area of lower legs was studied in later. We found irritant contact dermatitis in $11.45 \%$, whereas, this prevalence is much lower (5\%) in a study conducted in Imphal, India. However females were found to be affected more than males in both the studies. Pityriasis alba (5.72\%), pompholyx (2.08\%) and photo dermatitis (3.64\%) were found to be less frequent types of eczema, these are comparable to another study. ${ }^{11}$

In our study $15.62 \%$ patients had unspecified eczema. A study conducted in Ipswich, UK ${ }^{13}$ shows $40 \%$ patients suffered from eczemas which were grouped as unspecified.

\section{CONCLUSION}

From above study it can be concluded that contact dermatitis is most common form of eczema followed by hand dermatitis and seborhoeic dermatitits. Atopic dermatitis was found more frequently in children, while astetotic eczema was more frequent in old age.

Eczema is not an uncommon disease in our population. It affects not only patient's quality of life but also cause psycho-social problems.
Eczema is one of the major burden of skin diseases in our society. This study is a little contribution in the literature regarding the frequency of different types of eczema. Large scale population-based studies are required to determine the frequency of different forms of eczema as well as the prevalence of eczema in our population.

Copyright (C) 10 Dec, 2015.

\section{REFERENCES}

1. Holden CA, Berth-Jones J. Eczema, Lichenification, Prurigo and Erythroderma, In: Burns T, Breathnach S, Cox N, Griffith C. Rook's Textbook of Dermatology $8^{\text {th }}$ Ed. Oxford: Wiley-Black Well; 2010. P 17.1.

2. Happle R. Classification of eczema: an approach using pathogenetic criteria. Eur J Dermatol 1993; 3: 347-50.

3. Mackenzie-wood AR, Freeman S, Unclassified exogenous eczema. Contact dermatitis 1999; 41: 1821.

4. Maryum H, Alam MZ, Ahmsd I. Pattern of skin diseases in a tertiary care private hospital, Karachi. J Pak Assoc Dermatol. 2014; 24: 292-7.

5. Johonson MLT, Robert R. Skin Conditions and Related Needs for Medical Care among Persons 1-74 Years of Age. Washington DC: US Department of Health Education, National Centre for Health Statistics. 1978: Series II; No 212.

6. Muzaffar F. Pattern of skin diseases at the children's Hospital Lahore: Comparason between 1996- 1998 and 2011. J Pak Assoc Dermatol. 2012; 22: 230-6.

7. Devi T, Zamzachin G, Pattern of skin diseases in Imphal. Indian J Dermatol. 2006; 51: 149-50.

8. Ahmed A, Islam A, Sarkar S, Mia A. Pattern of different skin diseases among outdoor patients attended Faridpure Medical College Hospital, Faridpure, Bangladesh. Faridpur Med Coll J. 2010; 5: 53-5.

9. Shaw TE, Currie GP, Koudelka CW et al. Eczema Prevalence in United States: Data from the 2003 National Survey of Children's Health. J Invest Dermatol 2010; 10: 251-7.

10. Abhijit M, thappa D. Patterns of lower leg and foot eczema in South India. Indian J Dermatol Venerol Leprol 2008; 74: 458-61.

11. Ahmed I, Ansari M, Malick K. An audit of Dermatoses at Baqai Institute of skin diseases. J Pak Assoc 
Dermatol. 2003; 13: 113-7.

12. Uzma et al. Frequency of allergic contact dermatitis in hand eczema patients with European standards and corticosteroid series. J Pak Assoc Dermatol. 2013; 23: 289-294.

13. Horn R. The pattern of skin diseases in general practice. Dermatol Pract. 1986; Dec: 14-9.

14. Muzaffar F, Hussain I, Rashid T. An audit of childhood eczema. J Pak Assoc Dermatol 2000; 10: 21-25.

15. Hanifin JM, Reed ML. A population-based survey of eczema prevalence in United States. Dermatits 2007; 82: 82-91.

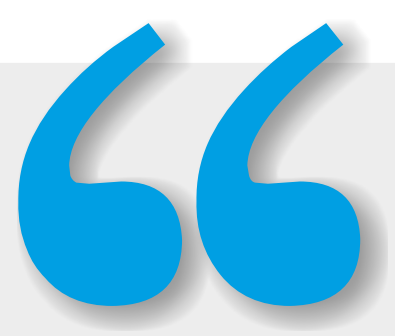

\section{"The true sign of intelligence is not knowledge but imagination."}

\section{Albert Einstein}

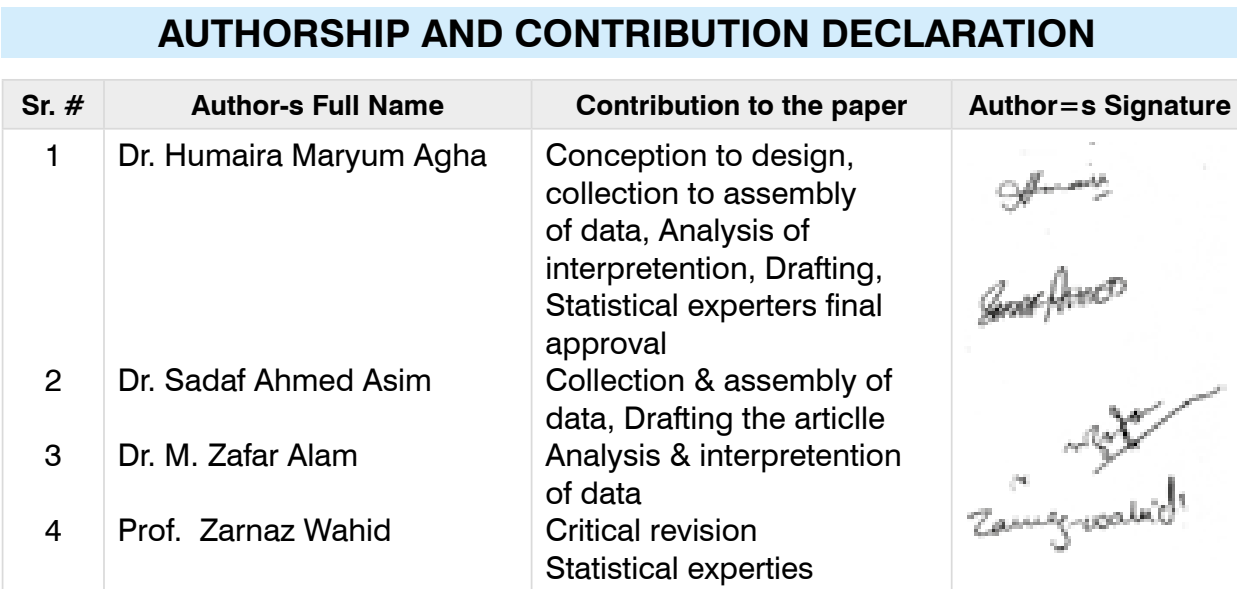

